\title{
Quantitative HPLC analysis of phenolic acids, flavonoids and ascorbic acid in four different solvent extracts of two wild edible leaves, Sonchus arvensis and Oenanthe linearis of North-Eastern region in India
}

\author{
Tapan Seal ${ }^{*}$ \\ Plant Chemistry Department, Botanical Survey of India, India.
}

\begin{tabular}{l}
\hline ARTICLE INFO \\
\hline Article history: \\
Received on: $24 / 11 / 2015$ \\
Revised on: $10 / 12 / 2015$ \\
Accepted on: $28 / 12 / 2015$ \\
Available online: $27 / 02 / 2016$ \\
\hline
\end{tabular}

Key words:

Phenolic compounds ; Ascorbic acid; Different solvent extracts; Sonchus arvensis; Oenanthe linearis; Gradient HPLC.

\begin{abstract}
A reversed-phase high-performance liquid chromatographic method using photodiode array detector with gradient elution has been developed and validated for the simultaneous estimation of ascorbic acid, free phenolic acids and flavonoids (catechin, rutin, quercetin, myrecetin, apigenin and Kaempferol) in four different solvent extracts of two wild edible leaves of viz. Sonchus arvensis and Oenanthe linearis, collected from North-eastern region in India. The chromatographic separation was carried out on Acclaim C 18 column $(5 \mu \mathrm{m}$ particle size, $250 \times 4.6 \mathrm{~mm}$ ), Dionex Ultimate 3000 liquid chromatograph and detection was carried out at three different wave lengths $(272,280$ and $310 \mathrm{~nm})$ using a mobile phase of acetonitrile and $1 \%$ aqueous acetic acid solution with gradient elution. The experimental results showed high amount of ascorbic acid in $S$. arvensis and $O$. Linearis $(1.2 \%$ and $2.3 \%$ respectively) and gallic acid $(0.02 \%$ and $0.06 \%$ respectively) in $1 \%$ aq. acetic acid extract of these two plants. The high percentage of recovery (96-103\%), low coefficient of variation $\left(R^{2}>0.99\right)$ and low limit of detection (LOD) and limit of quantitation (LOQ) confirm the suitability of the method for simultaneous quantification of ascorbic acid and all phenolic compounds in the two plants under investigation.
\end{abstract}

\section{INTRODUCTION}

The flavonoids are a large family of polyphenolic compounds synthesized by plants and structurally derived from the parent substance flavone. Flavonoids present in fruits and leafy vegetables are thought to provide potential and versatile health benefits through radical scavenging and chelating activity. The in-vitro antioxidant activities of the flavonoids are due to their ability to reduce the free radical formation and hence exhibit several biological activities.

Many studies have suggested that flavonoids like rutin, kaempferol, quercetin, apigenin etc. are well-known for its antiinflammatory, anti-allergic, anti-thrombitic, hepatoprotective, anti-spasmodic and anticancer properties (Kumar, 2012). Each different fruits and leafy vegetables are capable to display different extent of antioxidant activities owing to the presence of varied amount of free phenolic and flavonol contents. Ascorbic

\footnotetext{
* Corresponding Author

E-mail: kaktapan65@yahoo.co.in,Tel/FAX : +91-33-26685771
}

acid, a water soluble vitamin is essential nutrient in human diets and found mainly in fruits and vegetables. Due to the remarkable antioxidant properties of this compound, it is widely employed in pharmaceutical and cosmetic industry and also exerted several biological activities (Prabhakar, 2010). Phenolic compoundsare ubiquitous in plants and these are secondary metabolites which shield the plants against UV- radiation or resist the pathogenic aggression.

The phenolic acids with common bio-genetic precursor, shikimic acid, are mostly found in the bound form and are classified into three main groups viz. benzoic acid derivative, hydroxycinnamic acid derivative and depsides. These groups are well-known for their analgesic, antipyretic, cholagogic, sedative and anti-biotic properties (Waksmundzka-Hajnos et al., 2007). The commonest is hydroxycinnamic acid which consists mainly of ferulic, p-coumaric, caffeic, sinapic acid etc. These acids occur chiefly in the form of ester of quinic acid or glucose e.g. chlorogenic acid. The derivatives of hydroxy benzoic acid include vanillic, protocatechuic, p-hydroxy benzoic acid etc. which are found predominantly as glycosides. 
Phenolic acids play a potential protective role against different kinds of oxidative damaged diseases through consumption of fruits and vegetables. The amazing antioxidant cum nutraceutical properties of phenolics attracted global attention over the past decades. The biological activities like antimutagenicity, anti-bacterial action, anti-viral activity, antiinflammatory traits, apoptotic actions etc. can only be rationalized by detecting and quantitating such compounds (Mattila, 2007). It is worthy to be noted that only long-term ingestion leads to mitigation.

Sonchus arvensis known as Jalynniar/Jakhain in Khasi belongs to the family Compositae. The leaves of this plant are eaten as salad by the Khasi and Jaintia tribal of north-eastern region in India. It is bitter in taste but its delicacy preferred by the local people. The plant is renowned for its sedative, diuretic, diaphoretic, antiseptic, hypnotic, expectorant properties and useful in the treatment of coughs in phthisis, bronchitis, asthma and pertussis (Chopra et al., 2006). Oenanthe linearis, another wild edible plant of the north-eastern region in India, recognized as Jatira by Khasi people, belongs to the family Apiaceae. The young stems and leaves are cooked or fried as vegetable. The leaves and young stems are also boiled and used to cure diarrhea and dysentery. The nutritive value and the antioxidant activities of these plants have already been studied by us. The leaves of these two plants are characterized by high protein content $(19.55 \%$ and $21.80 \%)$, low fat content $(2.46 \%, 1.56 \%)$ and substantial mineral content $(\mathrm{Na}, \mathrm{K}, \mathrm{Ca}$ etc.). The methanol extract of the leaves of $O$. linearis are reported to show high phenolic content $(40.59 \mathrm{mg}$ GAE/gm of dry extract) and strong DPPH radical scavenging activity ( $\mathrm{IC}_{50} 0.62 \mathrm{mg} / \mathrm{gm}$ of dry extract) whereas $S$. arvensis showed moderate antioxidant activities (Seal, 2011). Thus, the presence of an appreciable amount of ascorbic acid, flavonoids and phenolic acids in these plants are inferred. The antioxidant activities of the extractive solution represent an important parameter to evaluate the biological property of the plant. Therefore, it is necessary to characterize and quantify the important compounds present in the plant and also to validate the method of separation and identification of active constituents. The use of the plant in folk medicine and its nutraceutical role provide unequivocal testimony to the fact. The extraction of polyphenolic compounds from plant is highly depending on the polarity of the solvent because polar compound is easily extracted using polar solvent.

Thus, the solvent used for the extraction of bioactive compounds must be critically chosen because it will influence the quantity and quality of the final extract (NurSyukriah et al., 2014). Therefore this study was aimed to investigate the antioxidant potential and quantitative estimation of ascorbic acid, free phenolic acids such as gallic acid, methyl gallate, caffeic acid, syringic acid, ferulic acid p-coumaric acid, sinapic acid and flavonoids (catechin, rutin, quercetin, myrecetin, apigenin and Kaempferol) in four different solvent extracts (chloroform, methanol, $80 \%$ aq. ethanol, $1 \%$ aq. acetic acid) of two wild edible leaves of viz. $S$. arvensis and $O$. linearis, collected from
Meghalaya state of India (North-eastern region in India)using reversed phase HPLC with diode array detection.

\section{MATERIALS AND METHODS}

\section{Plant material}

The leaves of Sonchus arvensis and Oenanthe linearis were collected from the local market of Meghalaya state of India. It was duly authenticated and a voucher specimen was kept at the Department of Plant Chemistry of Botanical Survey of India under the Registry No. BSITS 4and BSITS 5 for future reference. The plant part was shed-dried, made coarse powder and stored in an air-tight container for extraction.

\section{Chemicals}

The standards chemicals like ascorbic acid, phenolic acids (gallic, caffeic, syringic, p-coumaric, ferulic, and sinapic), flavonoids (catechin, rutin, myricetin, quercetin, apigenin and kaempferol) were purchased from Sigma Chemical Co. (St. Louis, MO, USA) and the HPLC-grade solvents such as chloroform, methanol, water and acetic acid were purchased from Merck (Germany).

\section{HPLC equipment}

HPLC analyses were performed with Dionex Ultimate 3000 liquid chromatograph (Germany) with four solvent delivery system quaternary pump (LPG 3400 SD) including a diode array detector (DAD 3000) with $5 \mathrm{~cm}$ flow cell, a manual sample injection valve equipped with a $20 \mu$ l loop and Chromeleon 6.8 system manager as data processor. The separation was achieved by a reversed-phase Acclaim ${ }^{\mathrm{TM}} 120 \mathrm{C} 18$ column (5 $\mu \mathrm{m}$ particle size, i.d. $4.6 \times 250 \mathrm{~mm}$ ).

\section{Preparation of standard solutions}

The stock solution of concentration $1 \mathrm{mg} / \mathrm{ml}$ was prepared by dissolving $1 \mathrm{mg}$ ascorbic acid in $0.5 \mathrm{ml}$ HPLC-grade methanol followed by sonication for 10 minutes and the resulting volume was made up to $1 \mathrm{ml}$ with the solvent for the Mobile phase (acetonitrile and 1\% aq. acetic acid 1: 9). The same method was followed to prepare the standard stock solutions of the phenolic acids and the flavonoids. The sample solutions of the sample under investigation were prepared by further dilution of the standard solution with the mobile phase solvent system. The standard and sample solutions were filtered through $0.45 \mu \mathrm{m}$ PVDF-syringe filter and the mobile phase was degassed before the injection of the solutions.

\section{Extraction of plant samples using four solvents of different polarity}

One gm of each coarsely powdered leaf was extracted using $5 \mathrm{ml}$ chloroform with constant stirring for 24 hours at the ambient temperature. The extract so prepared was filtered and the plant residue so left was macerated with the same volume of fresh solvent, stirred and filtered. The process was repeated thrice and 
the extracts were combined. The extracts were finally filtered through $0.45 \mu \mathrm{m}$ PVDF membrane and the volume was made up to $10 \mathrm{ml}$ using the same solvent \& stored. The same processes were followed for the preparation of sample extract in methanol, $80 \%$ aq. ethanol and $1 \%$ aq. acetic acid solution.

\section{Chromatographic analysis of phenolic compounds and ascorbic acid}

The mobile phase contains $1 \%$ aq. acetic acid solution (Solvent A) and acetonitrile (Solvent B), the flow rate was adjusted to $0.7 \mathrm{ml} / \mathrm{min}$, the column was thermostatically controlled at $28^{\circ} \mathrm{C}$ and the injection volume was kept at $20 \mu \mathrm{l}$. A gradient elution was performed by varying the proportion of solvent $\mathrm{B}$ to solvent A. The gradient elution was changed from $10 \%$ to $40 \% \mathrm{~B}$ in a linear fashion for duration of $28 \mathrm{~min}$, from 40 to $60 \% \mathrm{~B}$ in 39 min, from 60 to $90 \% \mathrm{~B}$ in $50 \mathrm{~min}$. The mobile phase composition back to initial condition (solvent B: solvent A: 10: 90) in $55 \mathrm{~min}$ and allowed to run for another $10 \mathrm{~min}$, before the injection of another sample. Total analysis time per sample was 65 min. HPLC chromatograms were detected using a photo diode array UV detector at three different wavelengths (272, 280 and $310 \mathrm{~nm}$ ) according to absorption maxima of analysed compounds. Each compound was identified by its retention time and by spiking with standards under the same conditions. The quantification of the sample was done by the measurement of the integrated peak area and the content was calculated using the calibration curve by plotting peak area against concentration of the respective standard sample. The data were reported with convergence limit in triplicate.

\section{Validation method of quantitative HPLC analysis of phenolic acid and flavonoids}

According to the USP and ICH guidelines, there are various parameters to validate the reproducibility of the method viz. the effectiveness, the limit of detection (LOD), the limit of quantitation (LOQ), the linearity, the precision and the accuracy.
The effectiveness of the HPLC method was detected with the standard solutions of ascorbic acid, phenolic acids and the flavonoids. Generally, methanol of diverse composition is used as eluent but solvents like acetonitrile, acetic acid, formic acid are also reported in the literature. In this study, different proportion of acetonitrile and $1 \%$ aq. acetic acid was used to achieve the best resolution.

To ascertain the linearity, the stock solution of the standard $(1 \mathrm{mg} / \mathrm{ml})$ was diluted to six different concentrations (5, $10,20,30,40,60 \mu \mathrm{g} / \mathrm{ml}$ ) which were fed individually in triplicate to the HPLC system and the calibration curve so obtained by plotting peak area versus concentration for each sample where the square of the correlation coefficient $\mathrm{R}^{2}>0.99$ is indicative of the measure of linearity. The accuracy of the method was determined by application of the standard addition method. The leaves extract of $S$. arvensis and $O$. Linearis were spiked with two known concentration of calibration solutions $(20 \mu \mathrm{g} / \mathrm{ml}$ and $40 \mu \mathrm{g} / \mathrm{ml})$. The amounts of phenolic acids and flavonoids present in the investigated leaves were previously determined. For each standard compound, the percentage of recovery was calculated as follows Recovery $(\%)=($ amount found - amount contained $) /$ amount added $\times 100$

The high recovery rate in the range of $96-103 \%$ for the samples is indicative of efficacy \& consistency.

Limit of detection and limit of quantification were calculated using the following formula $\mathrm{LOD}=3.3(\sigma) / S$ and LOQ $=10(\sigma) / S$, where $(\sigma)=$ standard deviation of response (peak area) and $S=$ slope of the calibration curve.

The precision refers to the degree of proximity of the results expressible as \% relative standard deviation (RSD) of the retention time and the peak area. The repeatability of the retention time and peak areas $(\mathrm{Pa})$ were checked by injecting the mixed standard solutions at two concentration levels $(20 \mu \mathrm{g} / \mathrm{ml}$ and $40 \mu \mathrm{g} / \mathrm{ml})$ into the HPLC system. The RSD of retention time and peak areas were calculated for five replicate determinations.

Table 1: Retention time and parameters of calibration curve, precision and repeatability, LOD, LOQ and percent recovery study of standard ascorbic acid, phenolic acids and flavonoids for HPLC method validation.

\begin{tabular}{|c|c|c|c|c|c|c|c|c|c|}
\hline $\begin{array}{l}\text { Name of the } \\
\text { Standard }\end{array}$ & $\begin{array}{c}\text { Detected at } \\
\text { wavelength } \\
\lambda \mathrm{nm}\end{array}$ & Retention time & $\begin{array}{l}\text { RSD }(\%) \text { of the } \\
\text { retention time }\end{array}$ & $\begin{array}{c}\text { RSD }(\%) \text { of the } \\
\text { peak area at } \\
\text { conc } 20 \mu \mathrm{g} / \mathrm{ml}\end{array}$ & $\begin{array}{c}\text { RSD }(\%) \text { of } \\
\text { the peak area } \\
\text { at conc } 40 \\
\mu \mathrm{g} / \mathrm{ml}\end{array}$ & $\begin{array}{c}\text { Regression } \\
\text { Coefficient } \\
\mathbf{R}^{2}\end{array}$ & $\begin{array}{l}\text { LOD } \\
\mu \mathrm{g} / \mathrm{ml}\end{array}$ & $\begin{array}{l}\text { LOQ } \\
\mu \mathrm{g} / \mathrm{ml}\end{array}$ & $\begin{array}{c}\text { Percentage } \\
\text { of recovery } \\
(\%)\end{array}$ \\
\hline Ascorbic acid & 272 & 4.02 & 0.437 & 0.069 & 0.550 & 0.9981 & 0.045 & 0.136 & 96.05 \\
\hline Gallic acid & 272 & 6.01 & 0.178 & 0.014 & 0.011 & 0.9956 & 0.009 & 0.027 & 98.76 \\
\hline Catechin & 272 & 11.28 & 0.124 & 0.144 & 0.077 & 0.9970 & 0.089 & 0.270 & 97.45 \\
\hline Methyl gallate & 272 & 12.60 & 0.107 & 0.018 & 0.011 & 0.9949 & 0.012 & 0.035 & 98.02 \\
\hline Caffeic acid & 272 & 13.96 & 0.060 & 0.018 & 0.009 & 0.9969 & 0.011 & 0.033 & 96.40 \\
\hline Syringic acid & 272 & 14.33 & 0.085 & 0.313 & 0.018 & 0.9966 & 0.192 & 0.582 & 100.92 \\
\hline Rutin & 272 & 16.80 & 0.061 & 0.037 & 0.016 & 0.9970 & 0.023 & 0.070 & 97.27 \\
\hline P-coumaric acid & 272 & 18.37 & 0.051 & 0.079 & 0.005 & 0.9967 & 0.048 & 0.146 & 98.69 \\
\hline Sinapic acid & 272 & 19.29 & 0.059 & 0.148 & 0.019 & 0.9967 & 0.093 & 0.280 & 97.65 \\
\hline Ferrulic acid & 272 & 19.77 & 0.050 & 0.100 & 0.010 & 0.9970 & 0.062 & 0.187 & 97.76 \\
\hline Myrecetin & 272 & 23.49 & 0.053 & 0.253 & 0.090 & 0.9947 & 0.153 & 0.464 & 103.40 \\
\hline Quercetin & 272 & 29.02 & 0.050 & 0.223 & 0.122 & 0.9957 & 0.130 & 0.395 & 98.12 \\
\hline Apigenin & 272 & 33.16 & 0.050 & 0.032 & 0.012 & 0.9921 & 0.018 & 0.053 & 98.95 \\
\hline Kaempferol & 272 & 34.23 & 0.046 & 0.025 & 0.008 & 0.9906 & 0.013 & 0.041 & 97.93 \\
\hline
\end{tabular}

Note: RSD Relative standard deviation, LOD Limit of detection, LOQ limit of quantification. 


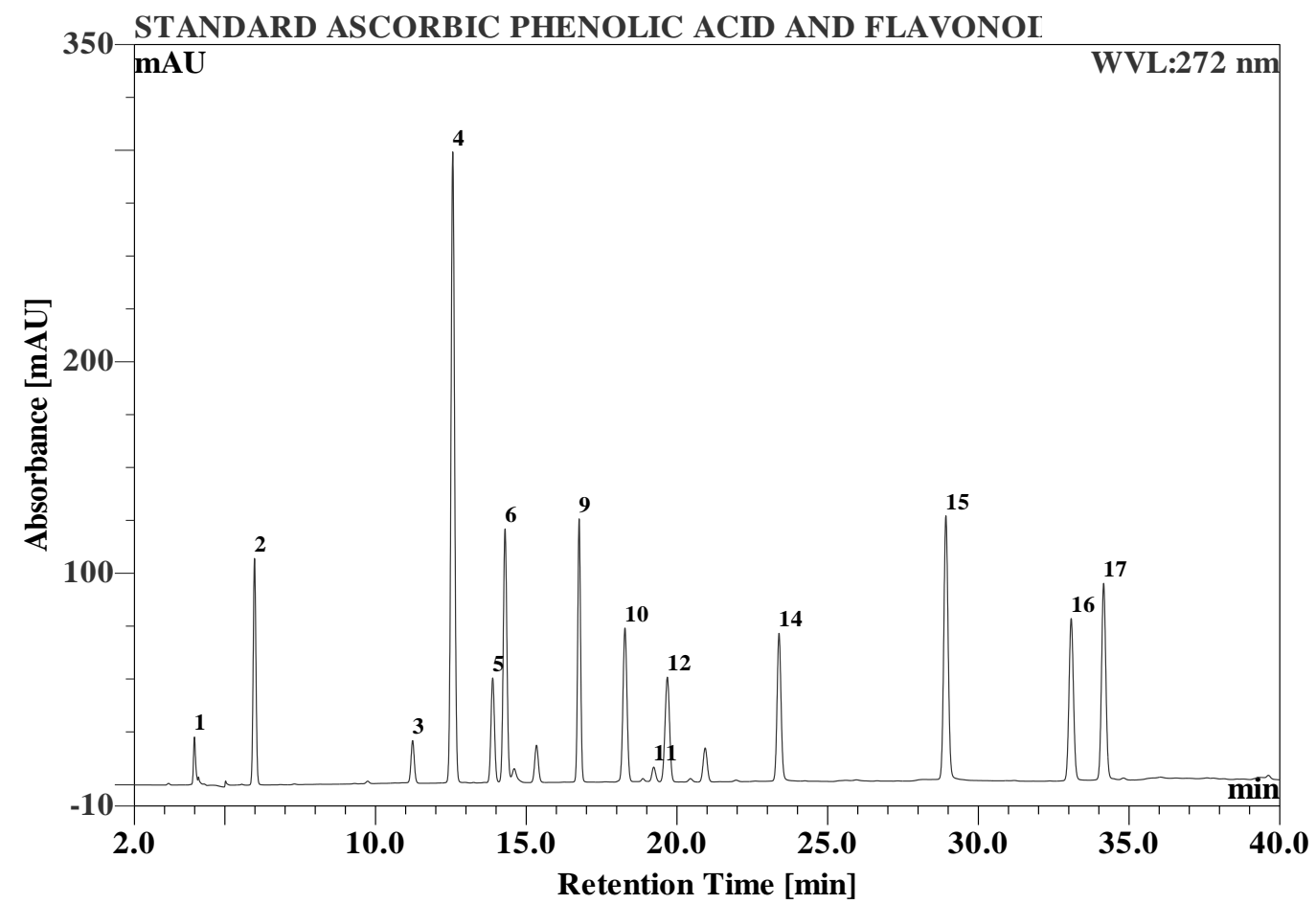

Fig.1: HPLC Chromatogram of standard ascorbic acid, phenolic acids and flavonoids.1.Ascorbic acid, 2. Gallic acid, 3. Catechin, 4. Methyl gallate, 5.Caffeic acid, 6. Syringic acid, 9. Rutin, 10. p-Coumaric acid, 11. Sinapic acid, 12. Ferrulic acid, 14. Myrecetin, 15. Quercetin, 16. Apigenin, 17.Kaempferol.

\section{RESULTS AND DISCUSSION}

Validation method of quantitative HPLC analysis of phenolic acid and flavonoids

A typical HPLC chromatogram of the all standard mixture recorded at $272 \mathrm{~nm}$ is presented in fig. 1. As shown in the chromatogram, all investigated compounds had responses at 272 $\mathrm{nm}$, where they were successfully separated. The constituents under investigation were also identified by the recorded absorption spectra, which were comparable both for leaf extracts of $S$. arvensis, $O$. linearis and standard substances. The regression coefficient together with LOD and LOQ values, are shown in Table 1.

The high value of $\mathrm{R}^{2}>0.9906$ in the range of analyzed concentrations at $272 \mathrm{~nm}$ is indicative of responsive linearity. The repeatability of the retention time for all the standard samples and that for the peak areas two standards viz., $20 \mu \mathrm{g} / \mathrm{ml}$ and $40 \mu \mathrm{g} / \mathrm{ml}$ was found to be below one percent.

The significant high rate of recovery of the standard phenolics and the flavonoids worth's mention. It follows that the method under consideration is characterized by precision, accuracy, meticulousness and can be used for the qualitative as also quantitative assay of ascorbic acid, the phenolics and the flavonoids in the leaf extract of these two plants under investigation .

Identification and quantification of different phenolic acids, flavonoids and ascorbic acid in four different extracts of the plant

The HPLC chromatogram of chloroform extract of $S$. arvensis showed the presence of quercetin and kaempferol whereas $O$. linearis contained caffeic acid, quercetin and apigenin as presented in fig. 2 and fig. 3 .

The methanol extract of the leaves of $O$. linearis revealed the presence of gallic acid, catechin, caffeic acid, syringic acid, quercetin and kaempferol but only quercetin was found in $S$. arvensis as depicted in the HPLC chromatogram in fig. 4 and fig. 5. The HPLC chromatogram of the $80 \%$ aq. Ethanol extract of both the plant indicated the presence of ascorbic acid, gallic acid, catechin and kaempferol in varying amounts as shown in fig. 6 and fig. 7. A small amount of caffeic acid, rutin, p-coumaric acid, ferulic acid and quercetin were also found in $O$. linearis. A remarkable amount of ascorbic acid and gallic acid were found in the $1 \%$ aq. acetic acid extract of the plants under investigation as shown in the HPLC chromatogram (fig. 8 and fig. 9). 


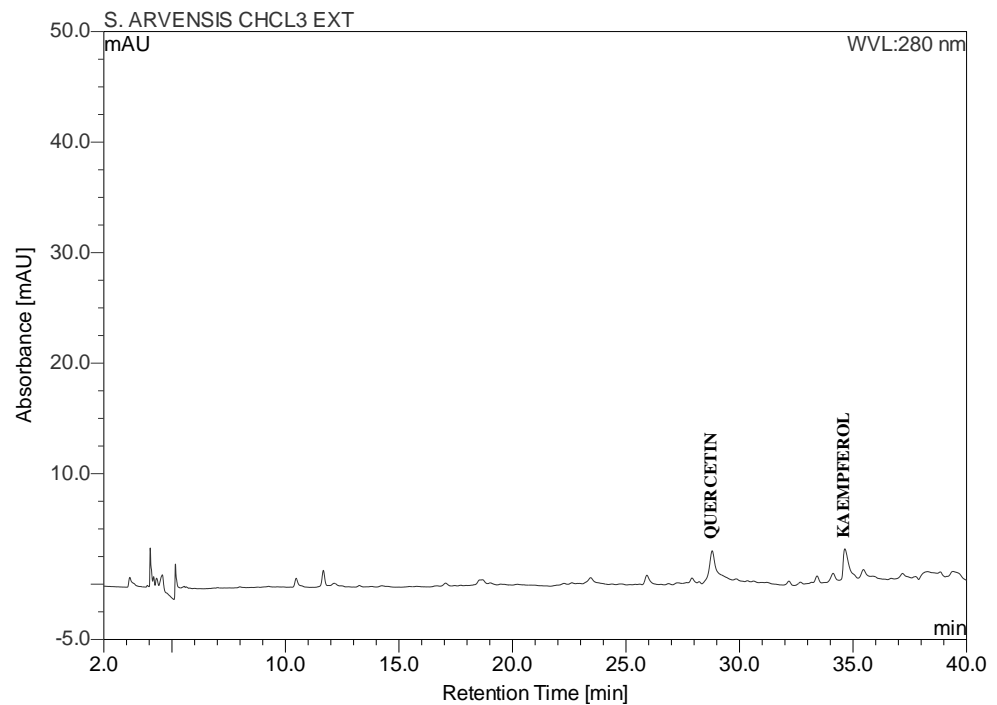

Fig. 2: HPLC chromatogram of the chloroform extract of S. arvensis

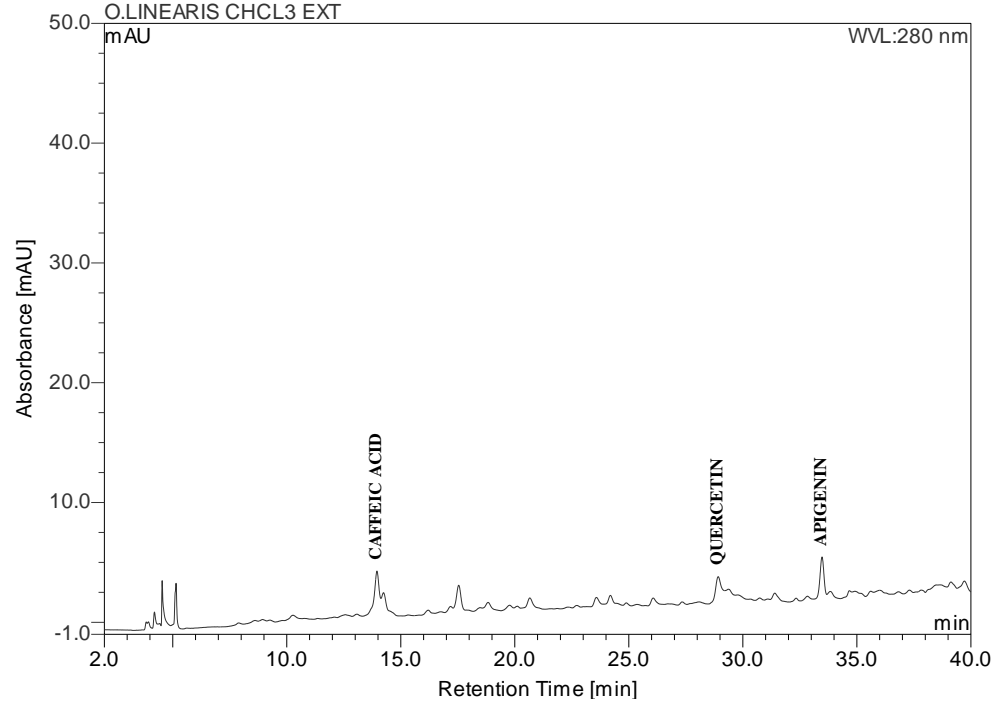

Fig. 3: HPLC chromatogram of the chloroform extract of $O$. linearis

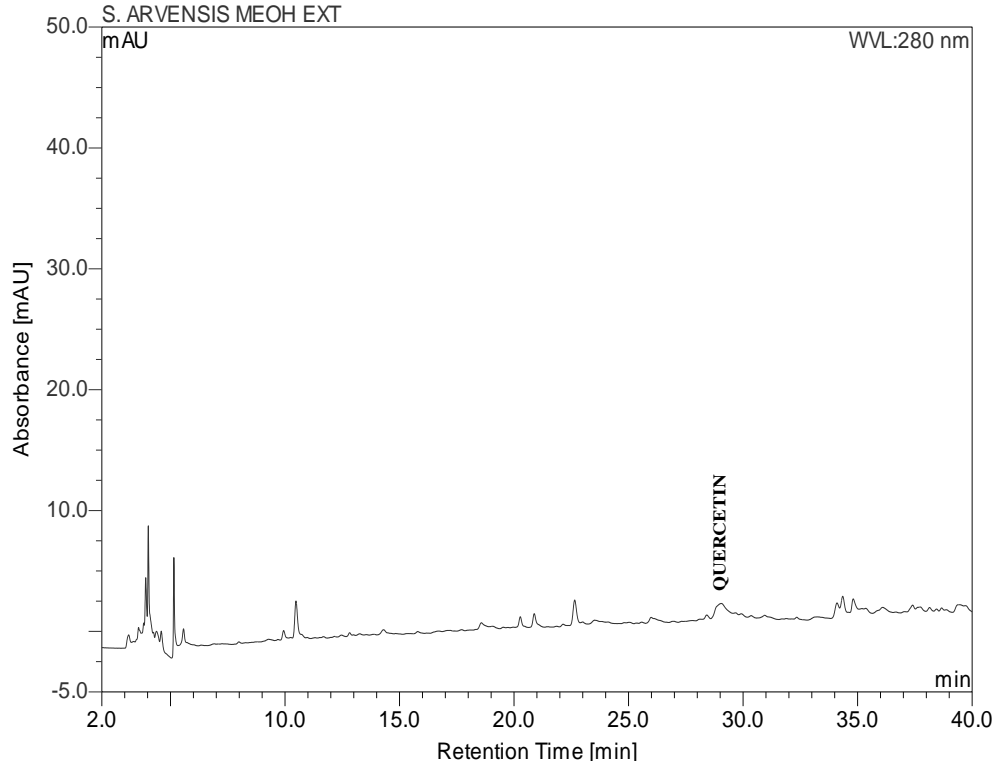

Fig. 4: HPLC chromatogram of the methanol extract of S. arvensis 


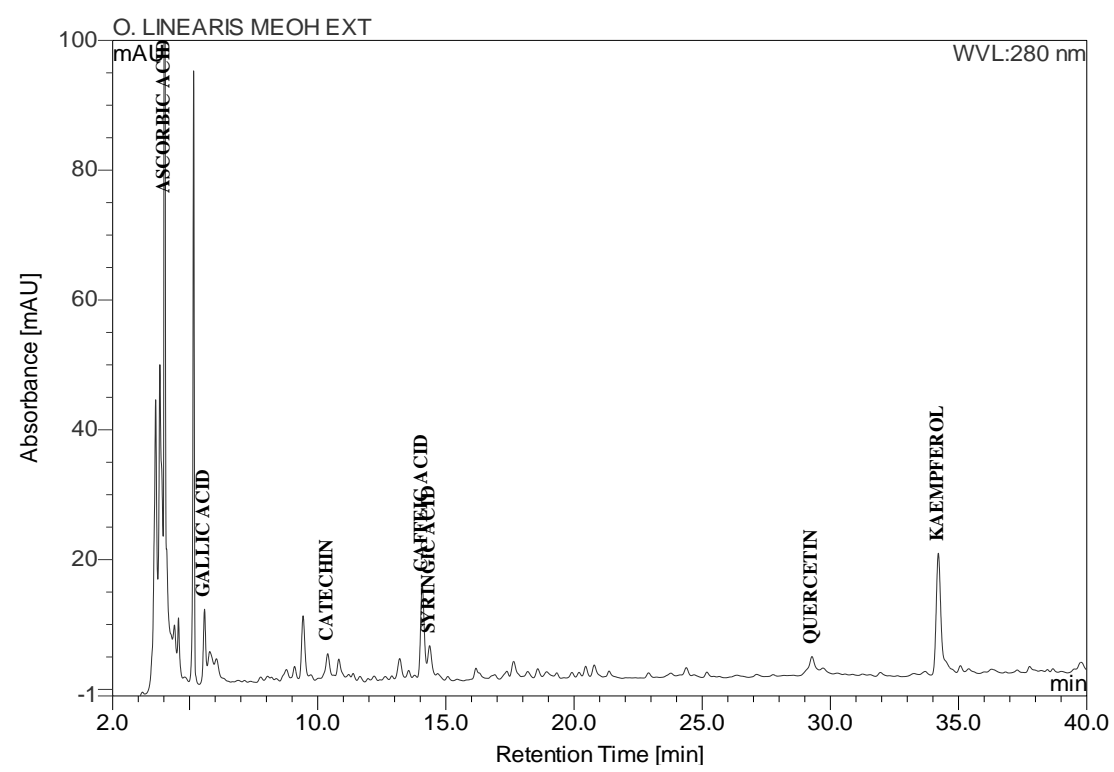

Fig. 5: HPLC chromatogram of the methanol extract of $O$. linearis.

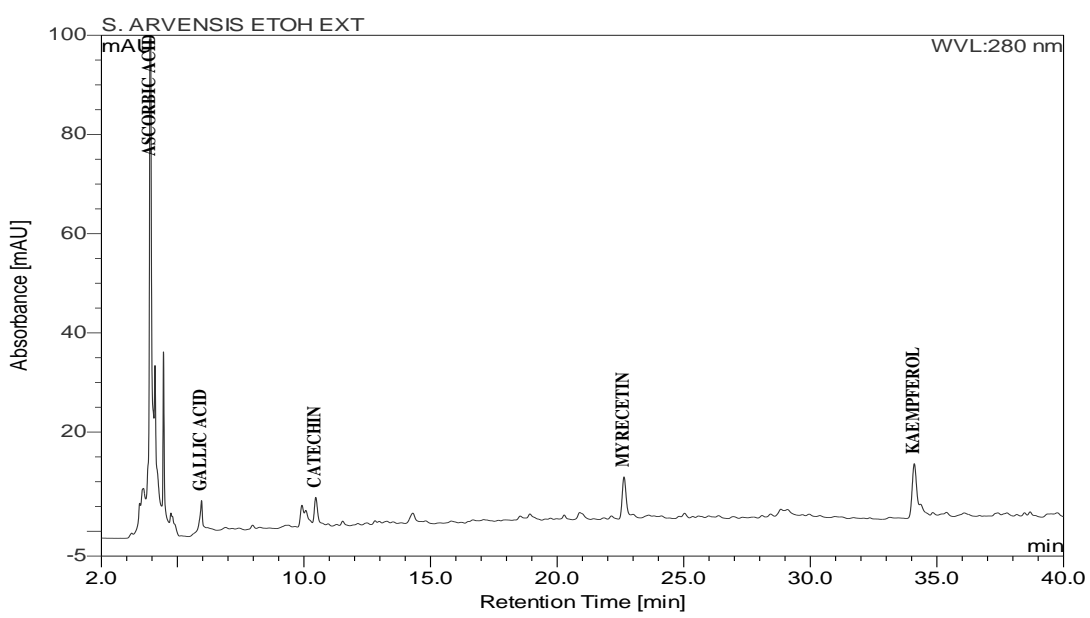

Fig. 6: HPLC chromatogram of the $80 \%$ ethanol extract of S. arvensis.

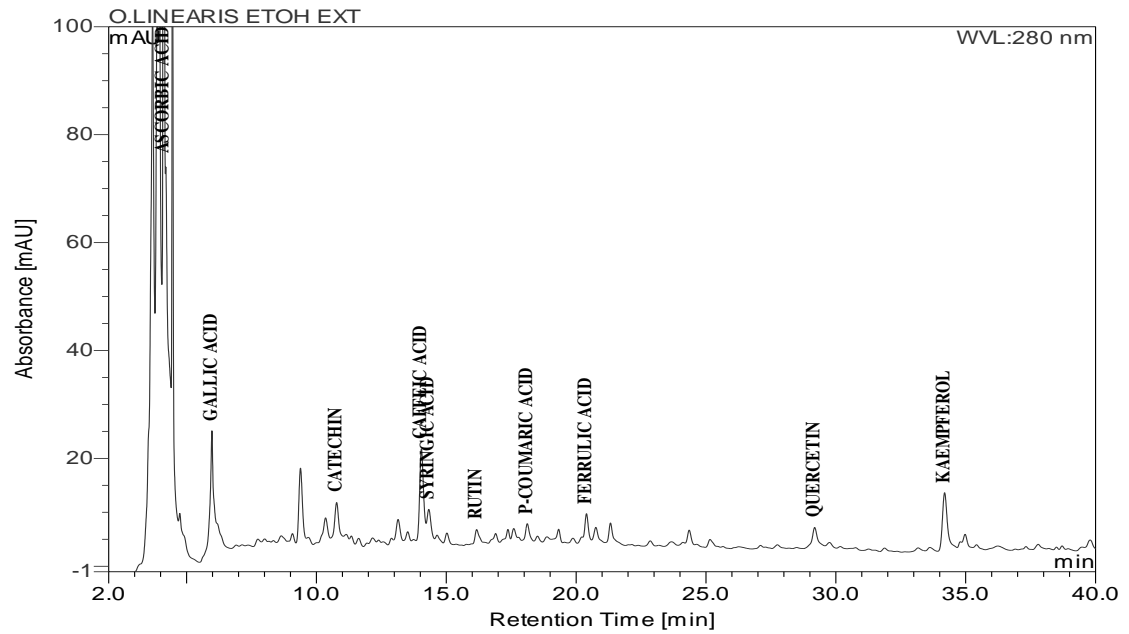

Fig. 7: HPLC chromatogram of the $80 \%$ ethanol extract of $O$. linearis 


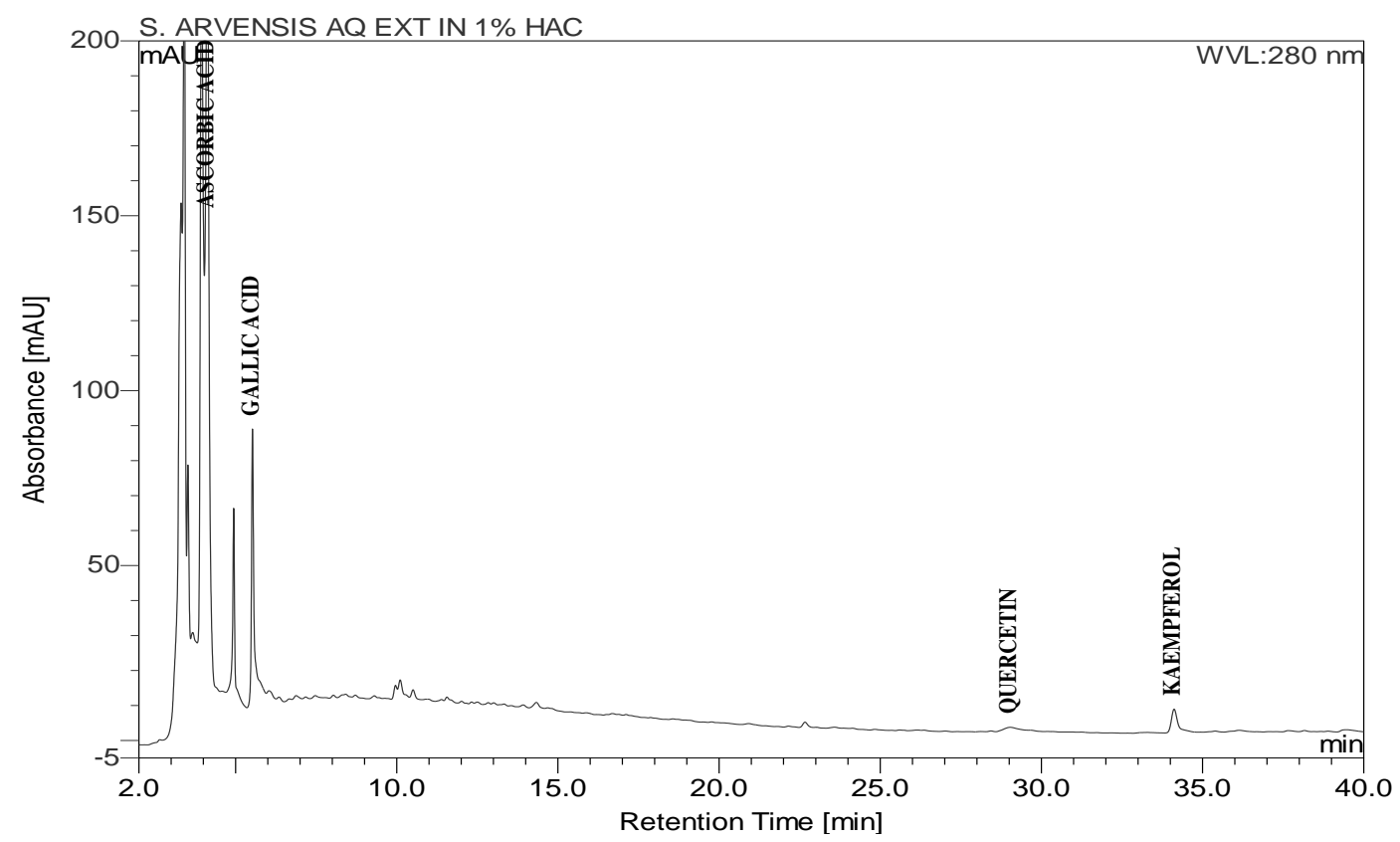

Fig. 8: HPLC chromatogram of the $1 \%$ aq. acetic acid extract of S. arvensis.

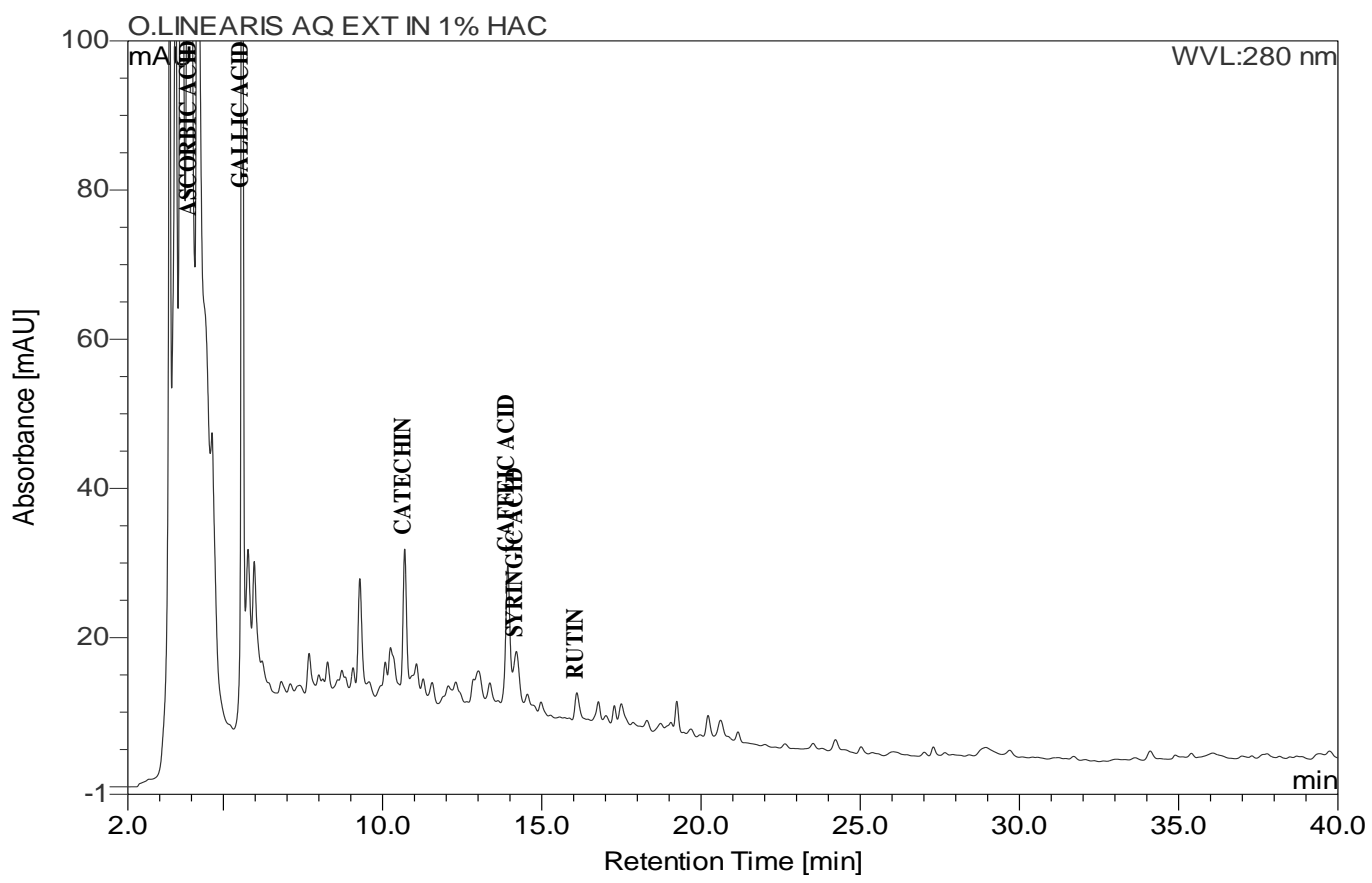

Fig. 9: HPLC chromatogram of the $1 \%$ aq. acetic acid extract of $O$. linearis.

It is noteworthy that the flavonoids, being comparatively less polar, were found mainly in the less polar media and that their quantity was found to be improved to some extent in polar media accounting for the synergistic effect of neighboring molecular architecture imposing restrictions on the freedom of -OH groups in the complex bio-matrix. Contrariwise, the elevated affection of the solvent polarity together with the concomitant cleavage of the ester linkage (as in depsides, for example) resulted in the increase in the content of the phenolic acids. However, both the effects came to a compromise and the $80 \%$ aq. ethanol containing maximum number as also the extent of the bio-active components was found to be the solvent of choice. 
Table 2: Quantification of ascorbic acids, phenolic acids and flavonoids in the four different extracts of S. arvensis and $O$. linearis.

\begin{tabular}{|c|c|c|c|c|c|c|c|c|}
\hline \multirow{3}{*}{$\begin{array}{l}\text { Ascorbic acid/ } \\
\text { phenolic acids } \\
\text { /flavonoids }\end{array}$} & \multicolumn{8}{|c|}{ Amount of ascorbic acid, phenolic acids and flavonoids $(\mathrm{mg} / \mathrm{gm})$ in the four different extracts of $S$. arvensis and $O$. linearis } \\
\hline & \multicolumn{4}{|c|}{ S. arvensis } & \multicolumn{4}{|c|}{ O. linearis } \\
\hline & $\begin{array}{c}1 \% \text { aq } \\
\text { Acetic acid }\end{array}$ & $\begin{array}{c}\mathbf{8 0 \%} \\
\text { Ethanol }\end{array}$ & Methanol & Chloroform & $\begin{array}{c}1 \% \text { aq } \\
\text { Acetic acid }\end{array}$ & $\begin{array}{c}\mathbf{8 0 \%} \\
\text { Ethanol }\end{array}$ & Methanol & Chloroform \\
\hline Ascorbic acid & $12.11 \pm 0.15$ & $6.23 \pm 0.05$ & Not detected & Not detected & $15.388 \pm 0.02$ & $7.580 \pm 0.04$ & $4.394 \pm 0.002$ & Not detected \\
\hline Gallic acid & $0.281 \pm 0.05$ & $0.05 \pm 0.0003$ & Not detected & Not detected & $0.628 \pm 0.001$ & $0.201 \pm 0.002$ & $0.034 \pm 0.0001$ & Not detected \\
\hline Catechin & Not detected & $0.136 \pm 0.004$ & Not detected & Not detected & $0.379 \pm 0.003$ & $0.204 \pm 0.001$ & $0.113 \pm 0.03$ & Not detected \\
\hline Methyl gallate & Not detected & Not detected & Not detected & Not detected & Not detected & Not detected & Not detected & Not detected \\
\hline Caffeic acid & Not detected & Not detected & Not detected & Not detected & $0.094 \pm 0.0001$ & $0.096 \pm 0.001$ & $0.076 \pm 0.04$ & $0.017 \pm 0.001$ \\
\hline Syringic acid & Not detected & Not detected & Not detected & Not detected & $0.046 \pm 0.002$ & $0.033 \pm 0.003$ & $0.027 \pm 0.003$ & Not detected \\
\hline Rutin & Not detected & Not detected & Not detected & Not detected & $0.073 \pm 0.005$ & $0.070 \pm 0.002$ & Not detected & Not detected \\
\hline p-coumaric acid & Not detected & Not detected & Not detected & Not detected & Not detected & $0.013 \pm 0.003$ & Not detected & Not detected \\
\hline Ferulic acid & Not detected & Not detected & Not detected & Not detected & Not detected & $0.023 \pm 0.002$ & Not detected & Not detected \\
\hline Myrecetin & Not detected & $0.110 \pm 0.004$ & Not detected & Not detected & Not detected & Not detected & Not detected & Not detected \\
\hline Quercetin & $0.043 \pm 0.0003$ & Not detected & $0.028 \pm 0.0003$ & $0.058 \pm 0.0004$ & Not detected & $0.046 \pm 0.001$ & $0.032 \pm 0.003$ & $0.065 \pm 0.003$ \\
\hline Apigenin & Not detected & Not detected & Not detected & Not detected & Not detected & Not detected & Not detected & $0.029 \pm 0.002$ \\
\hline Kaempferol & $0.094 \pm 0.0002$ & $0.157 \pm 0.002$ & Not detected & $0.045 \pm 0.0003$ & Not detected & $0.142 \pm 0.003$ & $0.248 \pm 0.002$ & Not detected \\
\hline
\end{tabular}

Each value in the table was obtained by calculating the average of three experiments and data are presented as Mean \pm SEM.

\section{Quantification of ascorbic acid, phenolic acids and flavonoids in four different extracts of the plant}

The present study indicated the occurrence of large amount of ascorbic acid and gallic acid in the $1 \%$ aq. acetic acid extract of both $S$. arvensis and $O$. linearis leaves in comparison to other extractive media as in table 2.

Ascorbic acid is ubiquitous in fruits and vegetables and the boon of ascorbic acid as nutraceutical in human nutrition dates back from time immemorial. The $1 \%$ aq. acetic acid extracts of both $O$. linearis and $S$. arvensis were found to contain the highest amount of ascorbic acid $(15.388 \pm 0.02 \mathrm{mg} / \mathrm{gm}$ and $12.11 \pm 0.15$ $\mathrm{mg} / \mathrm{gm}$ respectively) and gallic acid $(0.628 \pm 0.001 \mathrm{mg} / \mathrm{gm}$ and $0.281 \pm 0.05 \mathrm{mg} / \mathrm{gm}$ respectively) in comparison to the other less polar solvent like $80 \%$ aq. ethanol and methanol, used for extraction. An appreciable amount of ascorbic acids were also detected in the $80 \%$ ethanol extract of these plants and that could be well compared to that in commonly available edible plants, such as, Allium officinalis (1.90 mg/gm), Allium vineale (1.30 $\mathrm{mg} / \mathrm{gm})$, Chenopodium album $(1.30 \mathrm{mg} / \mathrm{gm})$, green peppers $(1.28$ $\mathrm{mg} / \mathrm{gm})$, lettuce $(0.18 \mathrm{mg} / \mathrm{gm})$, spinach $(0.51 \mathrm{mg} / \mathrm{gm})$, tomato (0.23 mg/gm) etc.(Zennie et al., 1977). This can be traced to the phylogenetic origin of the plant.

In the complex phyto-matrix, gallic acid remains either in the free state or in the combined form as ester and acts as a powerful antioxidant. The gallic acid content found in $80 \%$ ethanol extract of $O$. Linearis $(0.201 \pm 0.002 \mathrm{mg} / \mathrm{gm})$ and $S$. Arvensis $(0.05 \pm 0.0003 \mathrm{mg} / \mathrm{gm})$ are well compared to that in fruits such as, chilli pepper $(3.33 \mathrm{mg} / \mathrm{gm})$, lemon $(2.03 \mathrm{mg} / \mathrm{gm})$, spinach (1.82 $\mathrm{mg} / \mathrm{gm})$, onion bulb $(1.55 \mathrm{mg} / \mathrm{gm})$, cabbage $(0.49 \mathrm{mg} / \mathrm{gm})$ etc. (Romaric et al., 2011).

Catechins belong to a category of compounds known as flavanols and are found only in foods and drinks derived from plants. The $1 \%$ aq. acetic acid extract of $O$. linearis was found to contain the highest concentration of catechin amounting $0.379 \pm 0.003 \mathrm{mg} / \mathrm{gm}$. Appreciable quantities of catechin were detected in the $80 \%$ aq. ethanol extract $(0.204 \pm 0.001 \mathrm{mg} / \mathrm{gm})$ and in the methanol extract of the plant $(0.113 \pm 0.03 \mathrm{mg} / \mathrm{gm})$, signifying that polarity of the solvent was the important factor for the isolation of the bioactive constituents from plant. Catechin was also found only in the $80 \%$ ethanol extract of $S$. arvensis $(0.136 \pm 0.004 \mathrm{mg} / \mathrm{gm})$. This indicates that catechin found in both these plants may contribute to its medicinal and antioxidant properties. Caffeic acid is one of the major hydroxycinnamic acid components found in wine and it is a well- known antioxidant which boosts immunity, controls lipid levels in blood and antimutagenic. The acid is found mainly in the form of its ester (as in chlorogenic acid) in fruits, vegetables and herbs. The present study showed that all the four solvent extracts of $O$. Linearis were found to contain a very good amount of caffeic acid ranging from $0.017 \pm 0.001$ to $0.096 \pm 0.001 \mathrm{mg} / \mathrm{gm}$ and these were compatible with the same in cauliflower $(0.058 \mathrm{mg} / \mathrm{gm})$, carrot $(0.09 \mathrm{mg} / \mathrm{gm})$, lettuce $(1.57 \mathrm{mg} / \mathrm{gm})$ and potato $(2.80 \mathrm{mg} / \mathrm{gm})($ Schmidtlein, 1975$)$. Syringic acid with hydroxy benzoic acid skeleton is found in fruits and is well known for its anti-cancer, anti-proliferative, sedative, decongestant and hepato-protective actions (Vinayagam, 2010). Our investigation with these two plants showed that syringic acid was not found in any extract of S. arvensis, whereas the same was detected in the aq. acectic acid, $80 \%$ ethanol and methanol extracts of $O$. linearis in different concentrations. The content of the acid in the different extracts of Oenanthel eaves were higher than that reported for common leafy vegetables, such as, cauliflower (0.0113 mg/gm) (Ping et al. 1993), Salvia officinalis (0.0335 mg/gm), Origanum vulgare $(0.0375 \mathrm{mg} / \mathrm{gm})$ (Kivilompolo et al., 2007).

One of the important phenolics, ferulic acid, is wellknown for its physiology functions, such as, anti-microbial, antimicrobial, anti-inflammatory, anti-cancer activities etc. It also lowers cholesterol level in serum and increases sperm viability (Mussatto et al., 2007). It is the most widely distributed phenolics in cereal grain is ferulic acid which constitutes 0.8 to $2 \mathrm{gm} / \mathrm{Kg}$ (DW) of wheat grain where polyphenolics account for $90 \%$.

Another Hydroxycinnamic acid, p-coumaric acid, welldocumented for its antioxidant behaviour, is widely distributed in food stuffs, such as, barley, peanuts, navy beans, tomato, carrots etc. and is believed to have antioxidant behavior thereby reducing the formation of carcinogenic nitrosamines in the stomach 
(Ramadoss et al., 2015). The HPLC analyses of the two plants under investigation revealed that ferulic acid $(0.023 \pm 0.002 \mathrm{mg} / \mathrm{gm})$ and p-coumaric acid $(0.013 \pm 0.003)$ were present only in the $80 \%$ ethanol extract of $O$. linearis, indicating its higher antioxidant activities than $S$. arvensis.

Rutin is a phenolic compound with glycosidic linkage. It is reported to exhibit significant pharmacological activities, including anti-oxidation, anti-inflammation, anti-diabetic etc. It isalso used for the treatment of vericose veins, haemorrhoids, haemorrhagic stroke and mucositis. The rutin content in the extract of $1 \%$ aq. acetic acid $(0.073 \pm 0.005 \mathrm{mg} / \mathrm{gm})$ and in $80 \%$ aq. ethanol $(0.070 \pm 0.002 \mathrm{mg} / \mathrm{gm})$ of $O$. linearis were comparable to that in the leaves of Fagopyrum esculentum $(0.12 \mathrm{mg} / \mathrm{gm})$ and Melisa officinalis $(0.30 \mathrm{mg} / \mathrm{gm})$ (Moghaddasian et al., 2013). So the leaves of $O$. linearis plant might be considered as a good source of rutin and consumption of this plant as vegetable would be useful for health promotion.

Quercetin is distributed in distributed in different parts of plants of the plant not only as aglycones but also as glycosides and is known to impart luxuriant color to the fruits, flowers, leafy parts etc. It is reported to display anti-histamine, anti-cancer as also antiinflammatory activities which mostly follow its antioxidant traits. The dietary sources of quercetin include citrus fruits, apples, onions, parsley, sage, tea and red wine.

In fact, onion (Allium cepa L) is the richest source of quercetin $(2.60 \mathrm{mg} / \mathrm{gm})$ whereas a very good amount of this flavonol were found in chloroform extract of $S$. arvensis $(0.058 \pm 0.0004 \mathrm{mg} / \mathrm{gm})$ and O. linearis $(0.065 \pm 0.003 \mathrm{mg} / \mathrm{gm})$. An appreciable amount of quercetin, detected in the other extracts of both plants under study were comparable to the same in apple (0.021 mg/gm), lettuce $(0.011 \mathrm{mg} / \mathrm{gm})$ and tomato(0.055 mg/gm) (Wachet al. 2007).

The dietary adjuncts, such as, fruits, vegetables, spices, herbs etc are the rich source of apigenin, a flavone, which is known to reduce the risk of cardiac ailments, neurological syndromes, mutagenesis. It is reported that raw parsley is abundant in this nutraceutical $(3.02 \mathrm{mg} / \mathrm{gm})$ and the amount of this component detected only in the chloroform extract of the leaves of O. linearis $(0.029 \pm 0.002 \mathrm{mg} / \mathrm{gm})$ matched well with the harvested vegetables, such as, celery $(0.046 \mathrm{mg} / \mathrm{gm})$, cabbage $(0.0001$ $\mathrm{mg} / \mathrm{gm})$, sweet potato leaves $(0.0012 \mathrm{mg} / \mathrm{gm})$, peppermint $(0.087$ $\mathrm{mg} / \mathrm{gm}$ ) etc. (Mohammad, 2013). The leaf of $S$. arevensis was not found to contain apigenin at present study.

Among natural poly-phenolics, kaempferol, is a flavonol found in many edible plants and is reported to possess potent pharmacological and nutraceutical activities. The consumption of plants containing kaempferol thereby conferring innumerable health benefits in the form of reducing scourge of cardio vascular diseases, cancer, arteriosclerosis etc. The antioxidant properties are known to be responsible for these health benefits (Mohammad, 2013). The present investigation showed the presence of high kaempferol content in the $80 \%$ ethanol $(0.142 \pm 0.003 \mathrm{mg} / \mathrm{gm})$ and methanol extract $(0.248 \pm 0.002 \mathrm{mg} / \mathrm{gm})$ of O.linearis and also a very good amount was found in the $80 \%$ ethanol $(0.157 \pm 0.002$ $\mathrm{mg} / \mathrm{gm}$ ) extract of $S$. arvensis.

It is worthwhile to mention that the polarity increases the quantification of highly polar phenolic acids and a few flavonoids like rutin, quercetin and apigenin are detected in low concentration in the least polar solvent (Chloroform extract). However, the extract in aq. $80 \%$ ethanol is found to be the optimum solvent of choice as it contains the maximum variety and the extent of bioactive components.

\section{CONCLUSION}

The reversed-phase HPLC method with diode array detection was developed for the quantitative estimation of ascorbic acid, phenolic acids and flavonoids in the four different solvent extracts of $S$. arvensis and $O$. linearis. The established HPLC assay showed a well separation of the compounds and also the developed method was linear, sensitive, accurate, meticulous and reproducible. Therefore, the method is suitable for the simultaneous determination of phenolic acids and flavonoids in different formulations with 'shorter run time' and 'high efficiency'. The presence of significant amount of respective bioactive components in these plants under study and variation of quantity determined based on the polarity of the solvent taken for extraction process, ensures its unequivocal recommendation forthe use in the pharmaceutical and nutraceutical sector.

\section{ACKNOWLEDGEMENTS}

The Authors owe deep gratitude to Dr. P. Singh, Director, Botanical Survey of India, Kolkata for extending necessary scientific facilities and express sincere indebtedness to Mr. R. Shanpru, Scientist, Botanical Survey of India, North Eastern Circle, Shillong, Meghalaya for identifying the plant specimens.

\section{REFERENCES}

Chopra RN, Nayar SL and Chopra IC. 2006. Glossary of Indian Medicinal Plants. Seventh reprint, 170-241.

Kivilompolo M, Oburka V and Hyotylainen T. Comparison of GC-MS and LC-MS methods for the analysis of antioxidant phenolic acids in herbs. Analytical and Bioanalytical Chemistry, 2007; 388: 881-887.

Maheshkumar SK and Kirti SL. Determination of total flavonoids content and quantification of rutin in Momordica tuberosa (Roxb) Cogn. fruits by RP-HPLC. Asian Journal of Traditional Medicines, 2012;7: 220-25.

Mattila Pirjo, Hellstrom Jarkko. Phenolic acids in potatoes, vegetables, and some of their products. Journal of Food Composition and Analysis, 2007; 20: 152-160.

Moghaddasian B, Eradatmand $\mathrm{AD}$ and Alaghemand $\mathrm{A}$. Simultaneous determination of rutin and quercetin in different parts of Capparisspinose. Bull. Env.Pharmacol. Life Sci, 2013 ; 2 : 35- 38.

Mohammad A and Elham KK. Medicinal uses and chemistry of flavonoid contents of some common edible tropical plants. Journal of Paramedical Sciences, 2013;4 : 119-138.

Mussatto G, Dragone I and RobertoC. Ferulic and p-coumaric acids extraction by alkaline hydrolysis of brewer's spent grain. Industrial Crops and Products, 2007; 25: 231-237. 
NurSyukriah AR, Liza MS, Harisun Y and Fadzillah AAM. Effect of solvent extraction on antioxidant and antibacterial activities from Quercusinfectoria(Manjakani). International Food Research Journal, 2014; 21: 1067-1073.

Ping L, Xu-Qing W, Huai-Zhou W and Yong-Ning W. High performance liquid chromatographic determination of phenolic acids in fruits and vegetables. Biomedical and Environmental Sciences, $1993 ; 6: 389-398$.

Prabhakar B and Pandita N. Quantitative HPLC analysis of ascorbic acid and gallic acid in Phyllanthusemblica. J Anal Bioanal Techniques, $2010 ; 1: 111$.

Ramadoss Karthikeyan SI, Devadasu Chapala and Srinivasa Babu Puttagunta. Isolation, characterization, and RP-HPLC estimation of P-coumaric acid from methanolic extract of Durva Grass (Cynodondactylon Linn.)(Pers.). International Journal of Analytical Chemistry, 2015 ; 2015: 1-7.

Romaric GB; Fatoumata AL, Oumou HK, Mamounata D, Imael HNB and Mamoudou HD. Phenolic compounds and antioxidant activities in some fruits and vegetables from Burkina Faso. African Journal of Biotechnology, 2011;10: 13543-13547.

Schmidtlein $\mathrm{H}$. and Herrmann K. On the phenolic acids of vegetables. IV Hydroxycinnamic acids and hydroxybenzoic acids of vegetables and potatoes (GeL). Z. Lebensmittel. Untersuch.-Forsch., 1975 ;159: 255-263.

Seal T. Determination of Nutritive Value, Mineral Contents and Antioxidant Activity of Some Wild Edible Plants from Meghalaya State, India. Asian J Applied Sciences, 2011;4: 238-246.
Vinayagam,R. 2010. Preventive effect of Syringic acid on hepatic marker enzymes and lipid profile against acetaminophen-induced hepatotoxicity rats. International Journal of Pharmaceutical \& Biological Archives, 2010 ;1: 393-398.

Wach A, Pyrzyn'ska K and Biesaga M. Quercetin content in some food and herbal samples. Food Chemistry, 2007; 100: 699-704.

Waksmundzka-Hajnos, M, Oniszczuk A, Szewczyk K. And Wianowska D. Effect of sample-preparation methods on the HPLC quantitation of some phenolic acids in plant materials. Acta Chromatographica, 2007; 19: 227-37.

Zennie T. M. and Dwayne, O.C. Ascorbic acid and vitamin A content of edible wild plants of Ohio and Kentucky. Economic Botany, 1977; 31: 76-79.

\section{How to cite this article:}

Tapan Seal. Quantitative HPLC analysis of phenolic acids, flavonoids and ascorbic acid in four different solvent extracts of two wild edible leaves, Sonchus arvensis and Oenanthe linearis of North-Eastern region in India. J App Pharm Sci, 2016; 6 (02): 157166. 